\title{
Development of Overload Protection Using Current Sensing Feedback-Control Algorithm
}

\author{
Hsiung-Cheng Lin, ${ }^{*}$ Kuang-Pin Chen, ${ }^{1}$ Bo-Rong He, ${ }^{1}$ \\ Kai-Chun Hsiao, Heng-Chuan Zo, and Jui-Wen Chang ${ }^{1}$ \\ Department of Electronic Engineering, National Chin-Yi University of Technology, \\ No. 57, Sec. 2, Zhungshan Rd., Taiping District, Taichung City 41170, Taiwan \\ ${ }^{1}$ Aeronautical Systems Research Division, National Chung-Shan Institute of Science and Technology, \\ No. 481, Zhongzheng Rd., Longtan District, Taoyuan City 32546, Taiwan
}

(Received March 10, 2017; accepted May 1, 2017)

Keywords: LC filtering, feedback control, overload protection, high switching

Traditional methods to protect devices from overload usually use either fuses or electric breakers. However, the system is forced to stop working due to a disconnected power supply when the overload occurs incidentally. This may cause an unexpected risk in some circumstances. To resolve this problem, an overload protection system using a current sensing feedback-control mechanism is proposed in this study. First, the load current can be sensed and measured using a Hall sensor. The detected signal is then sent to the control circuit for an appropriate control signal to be generated to control the action of the switching circuit. The frequency of the control signal is determined by the predefined limited current without considering the load size. Based on a Fourier series transform, the harmonics of the output voltage can be reduced using LC filters so that only the dc term still remains. As a result, the load current can be smoothly maintained all the time. The experimental results confirm that the proposed scheme can effectively control the output current over an expected range.

\section{Introduction}

For safety considerations, powered electronic facilities such as motors or even power lines usually require the capability of overload protection. ${ }^{(1-4)}$ A circuit breaker is probably the most widely applied device to protect an electrical circuit from damage caused by over-current, overload, or short circuit. ${ }^{(5)}$ It is the reason that the Institute of Electrical and Electronics Engineers (IEEE) Standards announced the IEEE Recommended Practice for Applying Low-Voltage Circuit Breakers Used in Industrial and Commercial Power Systems in 2007. ${ }^{(6)}$ Information is provided for selecting the proper circuit breaker for a particular application, specifying the type of circuit breaker, ratings, trip functions, accessories, acceptance tests, and maintenance requirements. Recently, the IEEE Guide for Breaker Failure Protection of Power Circuit Breakers (IEEE Std C37.119-2016) was revised from IEEE Std C37.119-2005. ${ }^{(7)}$ Some methods were introduced to protect a power system from unclear faults because of failure of a power circuit breaker. In recent years, electronic circuit breakers have been improved to increase the quality of circuit breaker operations and reliability. ${ }^{(8-10)}$ For example, a SiC metal-oxide-semiconductor field-effect transistor (MOSFET) ${ }^{*}$ Corresponding author: e-mail: hclin@ncut.edu.tw http://dx.doi.org/10.18494/SAM.2017.1591 
DC circuit breaker based on a variable time-delay protection scheme was released. The cutoff operations take place after a proper delay time according to the transient properties of SiC devices and DC loads. ${ }^{(8)}$ A new type of DC circuit breaker to automatically and rapidly switch OFF in response to a fault was proposed. ${ }^{(9)}$ It has a crowbar type switch at the output so that it can act as a dc switch. A Z-source-based bidirectional DC circuit breaker that has fault current limitation and interruption capabilities was reported. ${ }^{(10)}$ It overcomes several essential challenges such as limiting and interrupting fault current in DC microgrids. Although these breakers have made good progress compared with traditional ones, they are more effective at protecting devices from overloads or short circuits.

Alternative approaches for overload protection have been based on DC-DC converters in past years. ${ }^{(11-13)}$ A double current limit technique for a high power buck converter was proposed to protect a converter from damage under any fault conditions. ${ }^{(11)}$ If the current increases up to some amount in a major overload or short circuit, the frequency of the buck converter can be decreased to limit the current. However, this voltage-mode buck converter is only capable of driving loads up to $3 \mathrm{~A}$ with a supply voltage from 8 to $30 \mathrm{~V}$. Another approach for overload protection was based on a predictive average current-mode control technique for digitally controlled DC-DC switchedmode power supplies. ${ }^{(12)}$ The current limit was suitable in a low-power case such as a controlled range of $6 \mathrm{~V}$ to $1.8 \mathrm{~V}$ with $10 \mathrm{~A}$. A flyback converter protection scheme with a selective shutdown delay time was proposed to protect a power MOSFET from various abnormal conditions. ${ }^{(13)}$ With this technique, the power supply may be shutdown immediately without a time delay for an output short condition. However, it was applied in a short-circuit situation. Another approach was focused on the design of a protection system for power semiconductor devices (PSDs) as applied to inverters and converters. ${ }^{(14)}$ However, this proposed system is used specifically for variable speed AC and DC drives, and it may not be suitable for general cases. An overload protection model based on heat effects was reported using a motor internal temperature-rise model. ${ }^{(15)}$ It is applicable in stable motor operation but unable to detect a sudden over-current change. In another case, a look-up table and Taylor expansion for over-current protection was recently released, but only for microcomputers. ${ }^{(16)}$ A new voltage control scheme of directly voltage-controlled distributed energy resource units can provide overcurrent protection in an islanded microgrid. The microgrid is restored to its normal operating conditions subsequent to fault clearance. Although this scheme limits the output current magnitude, it can not promise that a facility in the microgrid will work continuously and properly once the overcurrent has occurred. ${ }^{(17)}$

\section{The Proposed Model}

The structure of the proposed feedback-controlling high-switching LC algorithm for currentlimiting overload protection is simplified in Fig. 1(a), and its feedback-controlling mechanism is shown in Fig. 1(b). The proposed model contains a switching circuit and a control circuit. The control circuit includes a front comparator, inverter, timer, isolated circuit, rear comparator, and driver. More details are presented in Sect. 3. The switching circuit controls the switch's close/open period using the control signal generated from the control circuit. The controller, shown in Fig. 1(b), contains all parts of the control circuit except the front comparator that is used to detect the difference between the load current $\left(i_{O}\right)$ and predefined limited current $\left(I_{\text {limit }}\right)$. 


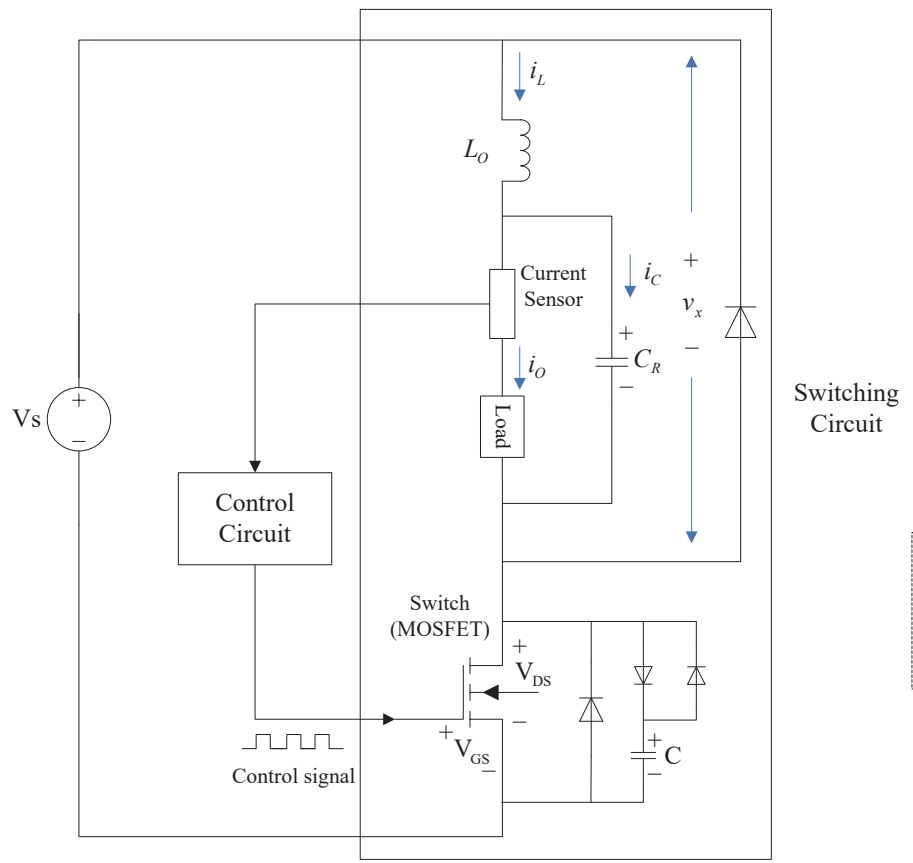

(a)

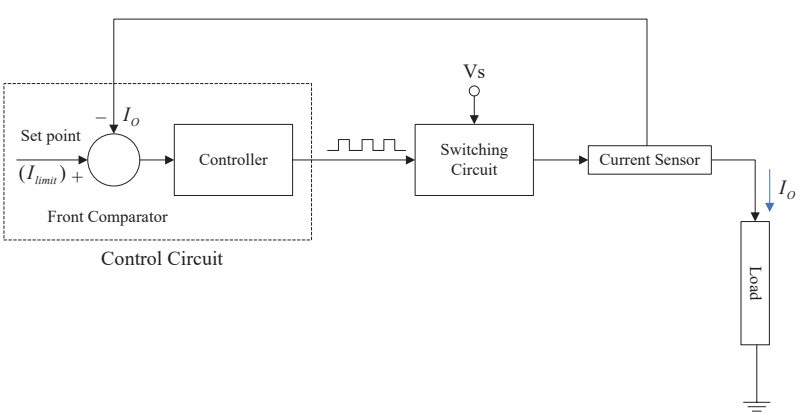

(b)

Fig. 1. Structure of the proposed model. (a) Structure of the model. (b) Feedback-controlling mechanism.

\section{Analysis of the Model}

\subsection{Control circuit}

The proposed control circuit is shown in Fig. 2. The current sensor uses a Hall effect-based current sensor (ACS712-30A) so that no load effect occurs. A detailed description follows.

\section{(a) Front comparator}

The current sensor using ACS712-30A produces a signal that is an output voltage with a linear relationship to the amount of load current $\left(i_{O}\right)$. Consequently, the input of the front comparator [shown in Fig. 3(a)] receives the output signal from the current sensor directly. At the beginning, the switch of the switching circuit [discussed in Section 3.2 (a)] is closed, and $i_{O}$ increases until it is beyond $I_{\text {limit }}$, where $I_{\text {limit }}$ is set by the adjustable resistor (5k) in advance. Once $i_{O}$ exceeds $I_{\text {limit }}$, the output immediately changes to a high voltage from a low voltage $(0 \mathrm{~V})$ and remains for a short time, shown in Fig. 3(b).

\section{(b) Inverter}

The inverter is connected to the output of the front comparator circuit [shown in Fig. 3(c)] to obtain a negative edge signal for triggering the timer soon after the overload current $I_{\text {limit }}$ appears. The waveforms of the input/output signals are shown in Fig. 3(d). 


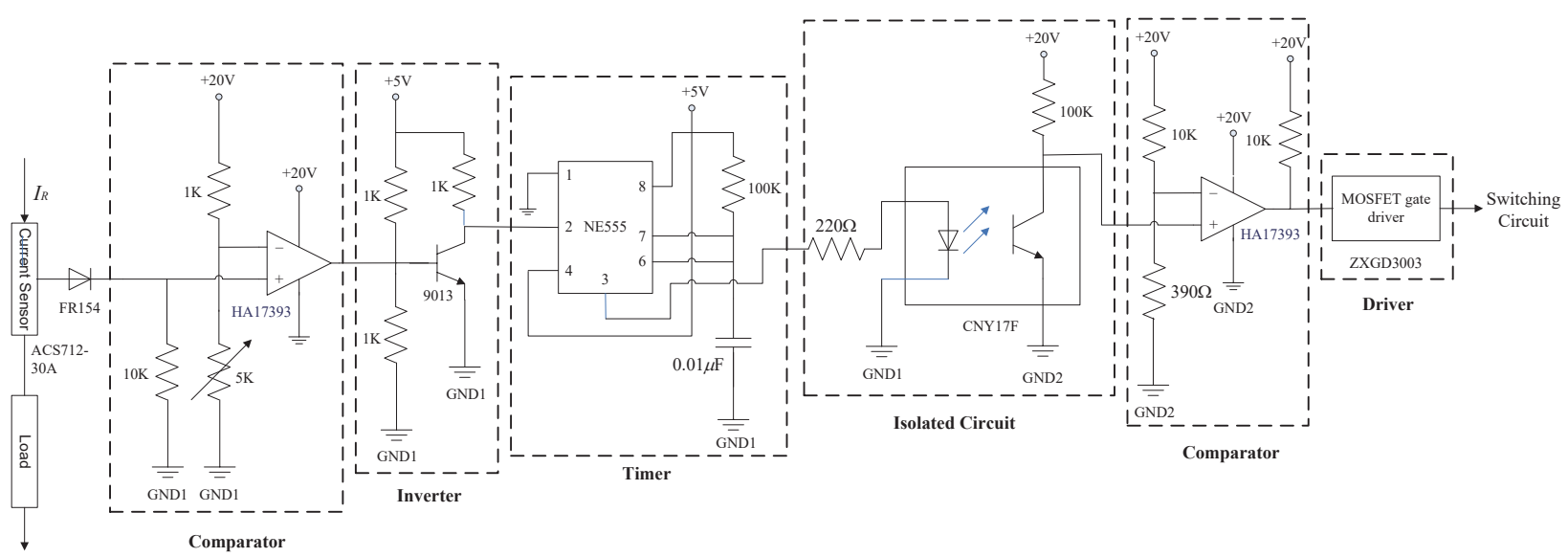

Fig. 2. Schematic of the control circuit.

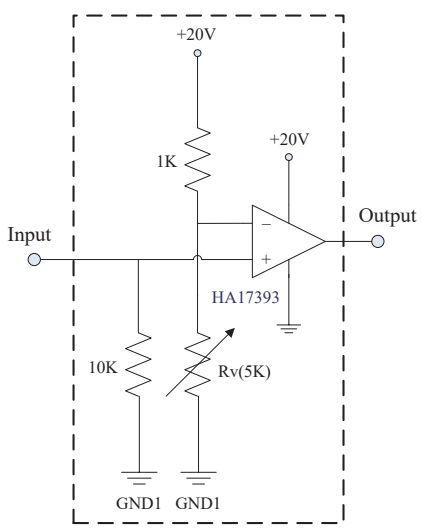

(a)

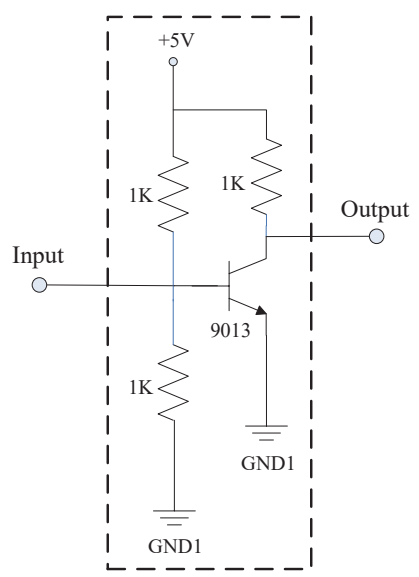

(c)

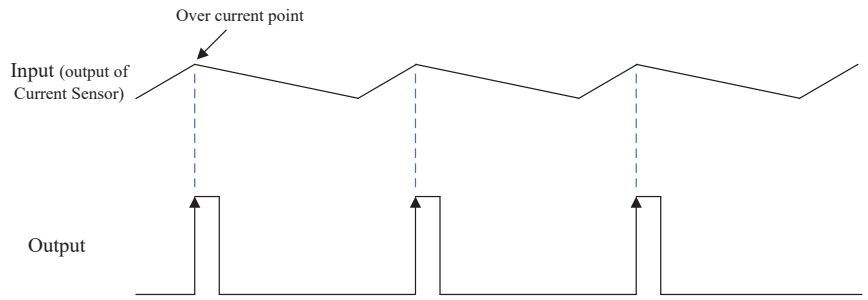

(b)

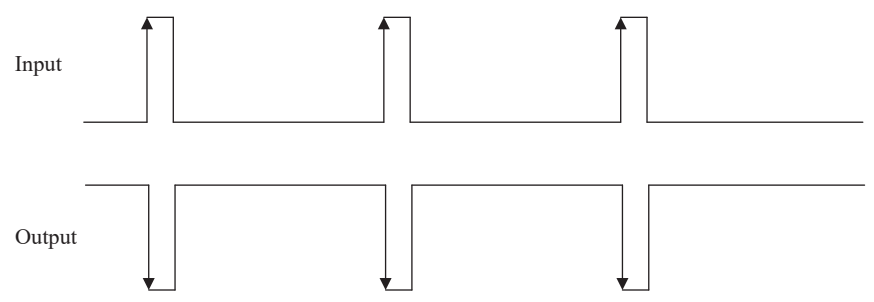

(d)

Fig. 3. (a) Front comparator and (b) waveforms of input/output signals. (c) Inverter circuit and (d) waveforms of input/output signals.

\section{(c) Timer}

The monostable (one-shot) circuit using a 555 timer is shown in Fig. 4(a). The input signal is originally from the front comparator circuit via the inverter. The delayed time is $1.1 \mathrm{RC}$, i.e., $1.1 \times$ 


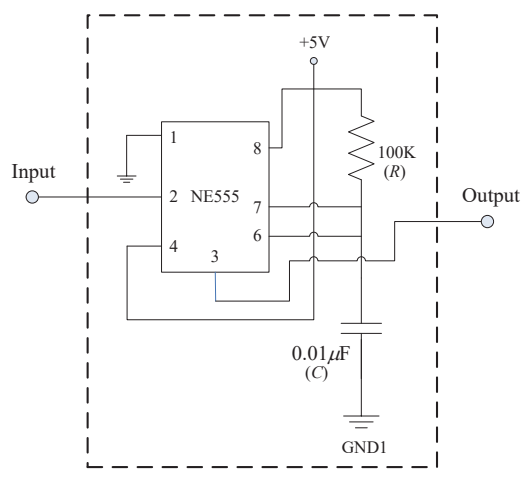

(a)

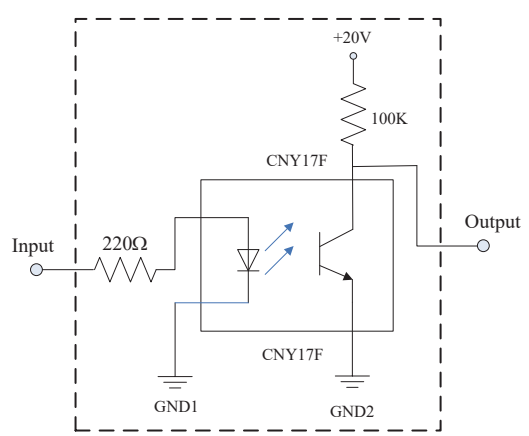

(c)

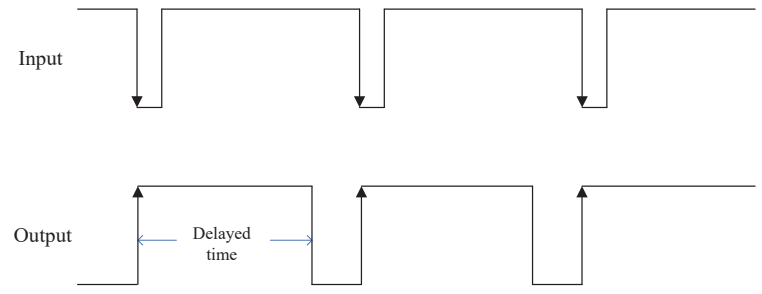

(b)

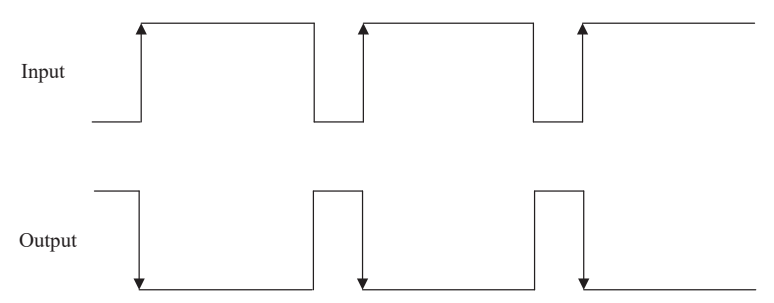

(d)

Fig. 4. (a) Monostable circuit and (b) waveforms of input/output signals. (c) Isolated circuit and (d) waveforms of input/output signals.

$100 \mathrm{k} \times 0.01 \mu \mathrm{F}=1.1 \mathrm{~ms}$, in this study. The relation between input/output signals is shown in Fig. 4(b). When the signal is at a low level, the negative edge signal triggers the timer and thus causes a delayed time period. This causes the switch to be opened for such a period sequentially.

\section{(d) Isolated circuit}

The CNY17 is an optically coupled pair that is used as the isolated circuit shown in Fig. 4(c). It separates the control circuit from the switching circuit. Therefore, the two circuits are isolated using different grounds (GND1 and GND2) to effectively avoid signal interference. The waveforms of the input/output signals are shown in Fig. 4(d).

\section{(e) Rear comparator}

The rear comparator circuit shown in Fig. 5(a) repairs the output of the isolated circuit and makes it an ideal digital signal. In practice, it guarantees a reliable trigger signal to be provided for the diver. The waveforms of input/output signals are shown in Fig. 5(b).

\section{(f) Driver}

The driver based on ZXGD3003 is used to control the MOSFET for fast action, as shown in Fig. 5(c). It is a high-speed non-inverting single MOSFET gate driver capable of driving up to $5 \mathrm{~A}$ into a MOSFET gate capacitive load from supply voltages of up to $40 \mathrm{~V}$. Note that the "off" period shown in Fig. 5(d) denotes the switch opened with a delay time, and "on" denotes the switch closed. 


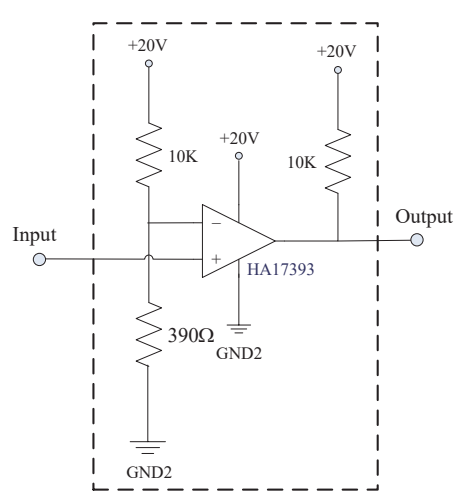

(a)

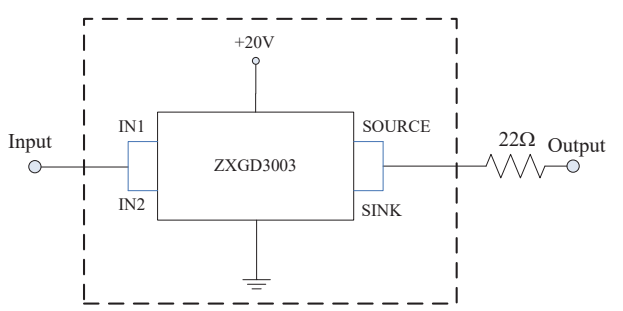

(c)

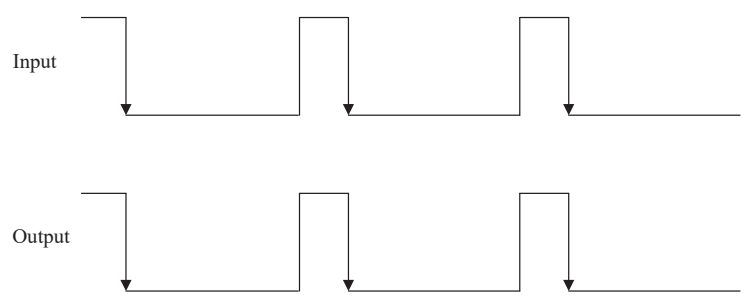

(b)

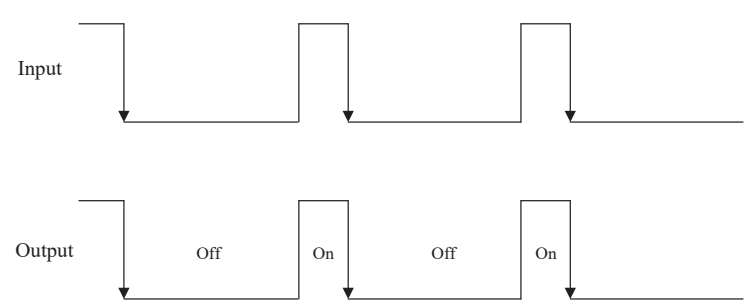

(d)

Fig. 5. (a) Rear comparator and (b) waveforms of input/output signals. (c) MOSFET driver and (d) waveforms of input/output signals.

\subsection{Analysis of switching circuit}

\section{(a) Without overload current limitation}

First, consider the switch closed all the time. In a stable condition, it produces a maximum current $\left(I_{\text {full }}\right)$ through the load, where the inductor acts as a short circuit and the capacitor acts as an open circuit. The switching circuit with a closed switch is simplified as in Fig. 6.

The term $I_{f u l l}$ can be simply calculated as

$$
I_{f u l l}=\frac{V_{S}}{R_{L}},
$$

where $R_{L}$ is the load resistor, $i_{L}=i_{O}$, and $V_{o}=V_{S}$.

\section{(b) With overload current limitation}

Second, consider the load current $\left(i_{O}\right)$ limited $I_{\text {limit }}\left(<I_{f u l l}\right)$. To achieve this purpose, the switch must be closed and opened alternatively at a certain frequency. The equivalent circuit of the switch circuit is depicted in Fig. 7(a), and its output waveform is shown in Fig. 7(b). The analysis assumes that the output filter produces a ripple-free voltage across the capacitor $\left(C_{O}\right)$, where $i_{O}=i_{L}$. When the load current $i_{O}$ reaches the limiting value $I_{\text {limit }}$, the switch is opened immediately for a certain period of time $(T-\tau)$, where $\tau$ is the period of time during the switch open status.

According to a Fourier series transform, the signal $v_{x}(t)$ can be expressed as 


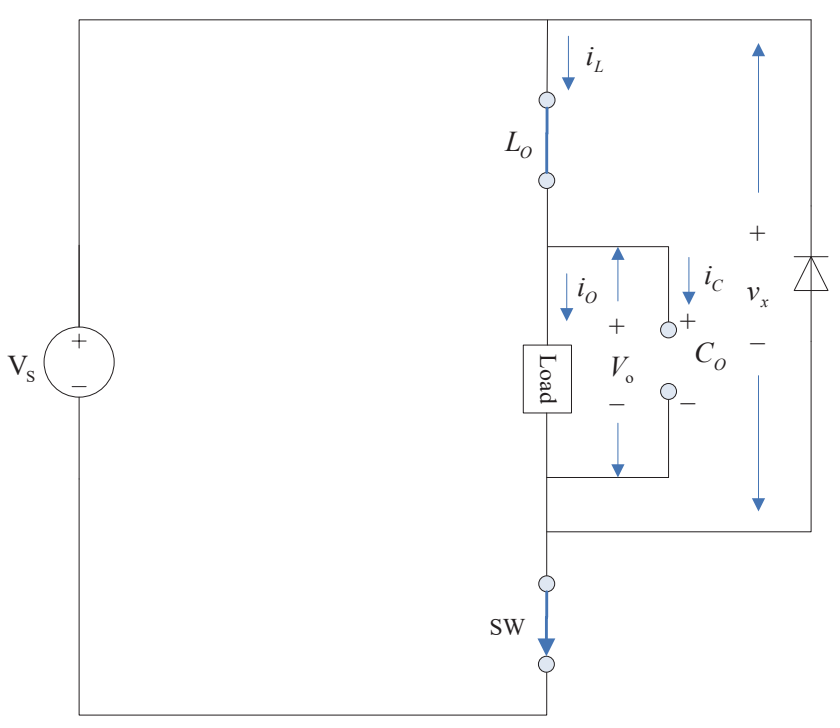

Fig. 6. The switching circuit with the switch closed in a stable condition.

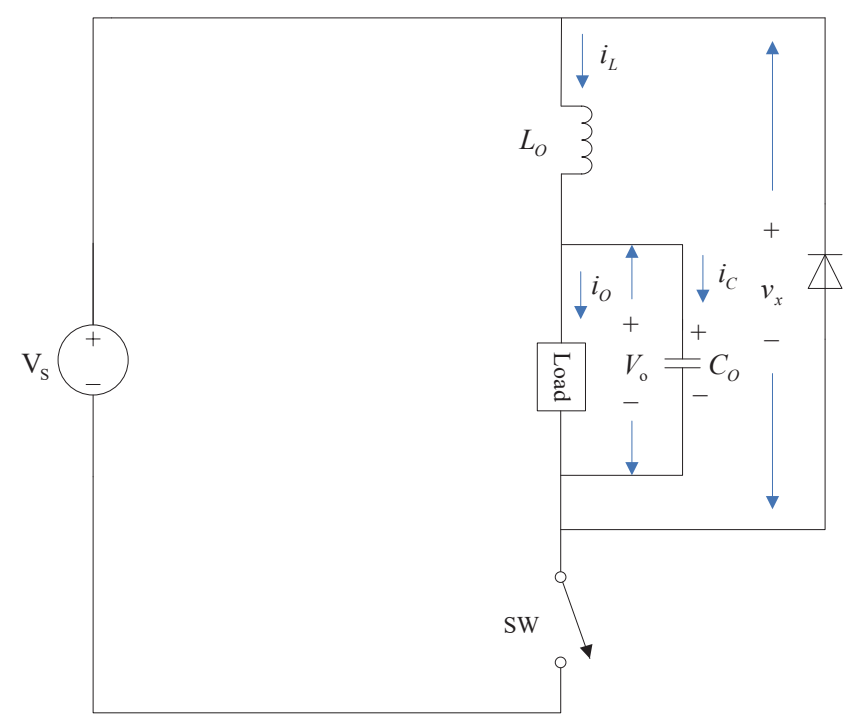

(a)

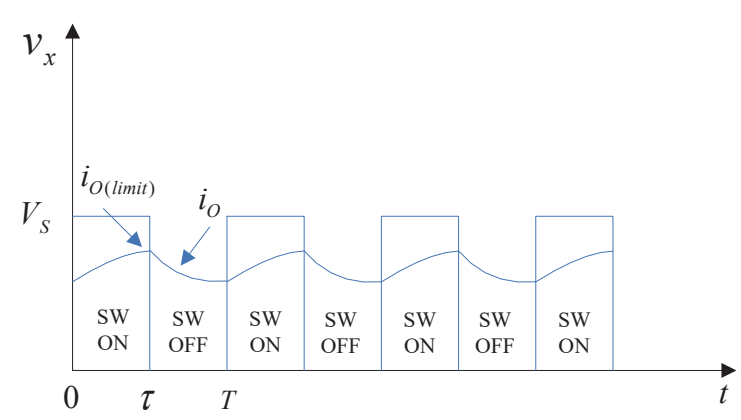

(b)

Fig. 7. Profile of switching circuit. (a) Equivalent circuit of switching circuit. (b) Waveforms of output signals.

$$
\begin{gathered}
v_{x}(t)=a_{0}+\sum_{n=1}^{\infty} a_{n} \cos n \omega t+\sum_{n=1}^{\infty} b_{n} \sin n \omega t, \\
a_{0}=\frac{1}{T} \int_{0}^{T} v_{x}(t) d t=\frac{V_{s} \tau}{T}, \\
a_{n}=\frac{2}{T} \int_{0}^{T} v_{x}(t) \cos n \omega t d t=\frac{V_{S}}{n \pi} \sin n \omega \tau,
\end{gathered}
$$




$$
b_{n}=\frac{2}{T} \int_{0}^{T} v_{x}(t) \sin n \omega t d t=\frac{V_{S}}{n \pi}(1-\cos n \omega \tau),
$$

where $\omega=2 \pi f$ and $f$ is the fundamental frequency of the signal.

Therefore, $v_{x}(t)$ can be obtained as

$$
v_{x}(t)=a_{0}+\frac{V_{S}}{\pi} \sum_{n=1}^{\infty} \frac{1}{n} \sin n \omega \tau \cos n \omega t+\frac{V_{S}}{\pi} \sum_{n=1}^{\infty} \frac{1}{n}(1-\cos n \omega \tau) \sin n \omega t .
$$

Equation (2) can be rewritten as

$$
\begin{gathered}
v_{x}(t)=c_{0}+\sum_{n=1}^{\infty} c_{n} \cos \left(n \omega t-\phi_{n}\right), \\
\text { where } c_{0}=a_{0}, c_{n}=\sqrt{a_{n}^{2}+b_{n}^{2}}, \phi_{n}=-\tan ^{-1}\left(\frac{b_{n}}{a_{n}}\right) . \\
c_{n}=\sqrt{a_{n}^{2}+b_{n}^{2}}=\frac{2 V_{S}}{\pi n} \sin \frac{n \omega \tau}{2} \\
\phi_{n}=-\tan ^{-1}\left(\frac{b_{n}}{a_{n}}\right)=-\tan ^{-1}\left(\tan \frac{n \omega \tau}{2}\right)=-\frac{n \omega \tau}{2} \\
\rightarrow v_{x}(t)=\frac{V_{S} \tau}{T}+\frac{2 V_{S}}{\pi} \sum_{n=1}^{\infty} \frac{1}{n} \sin \frac{n \omega \tau}{2} \cos \left(n \omega t-\frac{n \omega \tau}{2}\right)
\end{gathered}
$$

Since the average voltage across the inductor $\left(L_{O}\right)$ in the steady state is zero, the average output voltage $\left(V_{o}\right)$ for continuous inductor current $\left(i_{L}\right)$ is

$$
V_{o}=\frac{V_{S} \tau}{T}
$$

The average inductor current $\left(i_{L}\right)$ must be equal to the average load current $\left(i_{O}\right)$ as the average capacitor current $\left(i_{C}\right)$ is zero:

$$
i_{L}=i_{O}=\frac{V_{o}}{R_{L}}=\frac{V_{S} \tau}{T R_{L}}
$$

where $R_{L}$ is the load resistor.

The variation in inductor current $\left(i_{L}\right)$ can be estimated from the first ac term of $v_{x}(t)$ in the Fourier series. Assuming the capacitor to be a short circuit to ac terms, the first harmonic voltage $\left(v_{1}\right)$ exists across the inductor. The amplitude of the inductor current $i_{L}$ for $n=1$ is

$$
I_{1}=\frac{V_{1}}{Z_{1}} \approx \frac{V_{1}}{\omega L}=\frac{\frac{2 V_{S}}{\pi} \sin \frac{\omega \tau}{2}}{\omega L}=\frac{2 V_{S}}{\pi \omega L} \sin \frac{\omega \tau}{2}
$$


For the load current $\left(i_{O}=i_{L}\right)$ always to be positive, the amplitude of the first ac term must be less than the dc term (average value). Using the preceding equations and solving for $L_{O}$,

$$
\begin{gathered}
I_{1}<i_{L}, \\
\frac{2 V_{S}}{\pi \omega L_{O}} \sin \frac{\omega \tau}{2}<\frac{V_{S} \tau}{T R} \\
L_{O}>\frac{2 T R_{L}}{\pi \tau \omega} \sin \frac{\omega \tau}{2}=\frac{4 R_{L}}{\tau \omega^{2}} \sin \frac{\omega \tau}{2} \text { for continuous current }
\end{gathered}
$$

where $T=\frac{2 \pi}{\omega}$.

As above, if Eq. (14) is satisfactory, the inductor current $\left(i_{L}\right)$ is continuous and the output voltage $\left(V_{o}\right)$ is equal to $\frac{V_{S} \tau}{T}$.

\section{Model Verification}

To verify the proposed model based on this theoretical analysis, we selected $V_{S}=28 \mathrm{~V}, R_{L}=1 \Omega$, $L_{O}=100 \mu \mathrm{H}$, and $C_{O}=4700 \mu \mathrm{F}$ for further investigation.

$$
I_{f u l l}=\frac{V_{S}}{R_{L}}=\frac{28}{1}=28(\mathrm{~A})
$$

\subsection{Design of current limitation}

According to the datasheet of an ACS712 Hall current sensor (30 A) shown in Fig. 8, the variable resistor $R_{V}(5 \mathrm{k})$ in Fig. 3(a) can be adjusted to obtain the desired $I_{\text {limit }}\left(<I_{\text {full }}\right)$.

The value of $R_{V}$ is formulated with $I_{\text {limit }}$ as

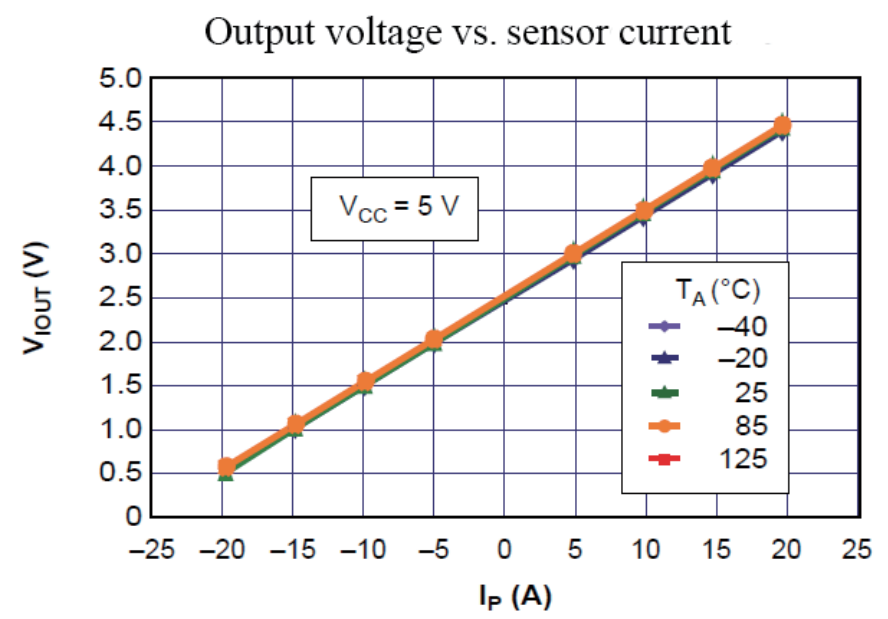

Fig. 8. (Color online) Datasheet of an ACS712 Hall current sensor (30A). 


$$
20 \times \frac{R_{V}}{R_{1}+R_{V}}=I_{\text {limit }} \times 0.066+2.5 \text { (reference voltage) }-0.5 \text { (diode voltage drop) }
$$

where $R_{1}=1 \mathrm{k}$.

From Eq. (15), $R_{V}$ is determined as

(a) $I_{\text {limit }}=10 \mathrm{~A} \rightarrow R_{V}=153 \Omega$

(b) $I_{\text {limit }}=20 \mathrm{~A} \rightarrow R_{V}=199 \Omega$

The following rule is built up based on the control principle described in Fig. 1(b):

(a) $i_{O} \geq I_{\text {limit }} \rightarrow$ Switch opened for a period time determined by the timer.

(b) $i_{O}<I_{\text {limit }} \rightarrow$ Switch remains closed until $i_{O}=I_{\text {limit }}$. The length of $T$ is related to $I_{\text {limit }}$, and increasing $I_{\text {limit }}$ will cause longer $T$ in practice.

The performance analysis waveforms are shown in Fig. 9.

\subsection{Experimental results}

Practical work has been carried out to verify this proposed model. Various waveforms acquired from different locations of a control circuit at $I_{\text {limit }}=10$ A are shown in Fig. 10. Note that $100 \mathrm{mV}$ on the scale denotes $1 \mathrm{~A}$ for $i_{O}$ as shown in Fig. 10(d).

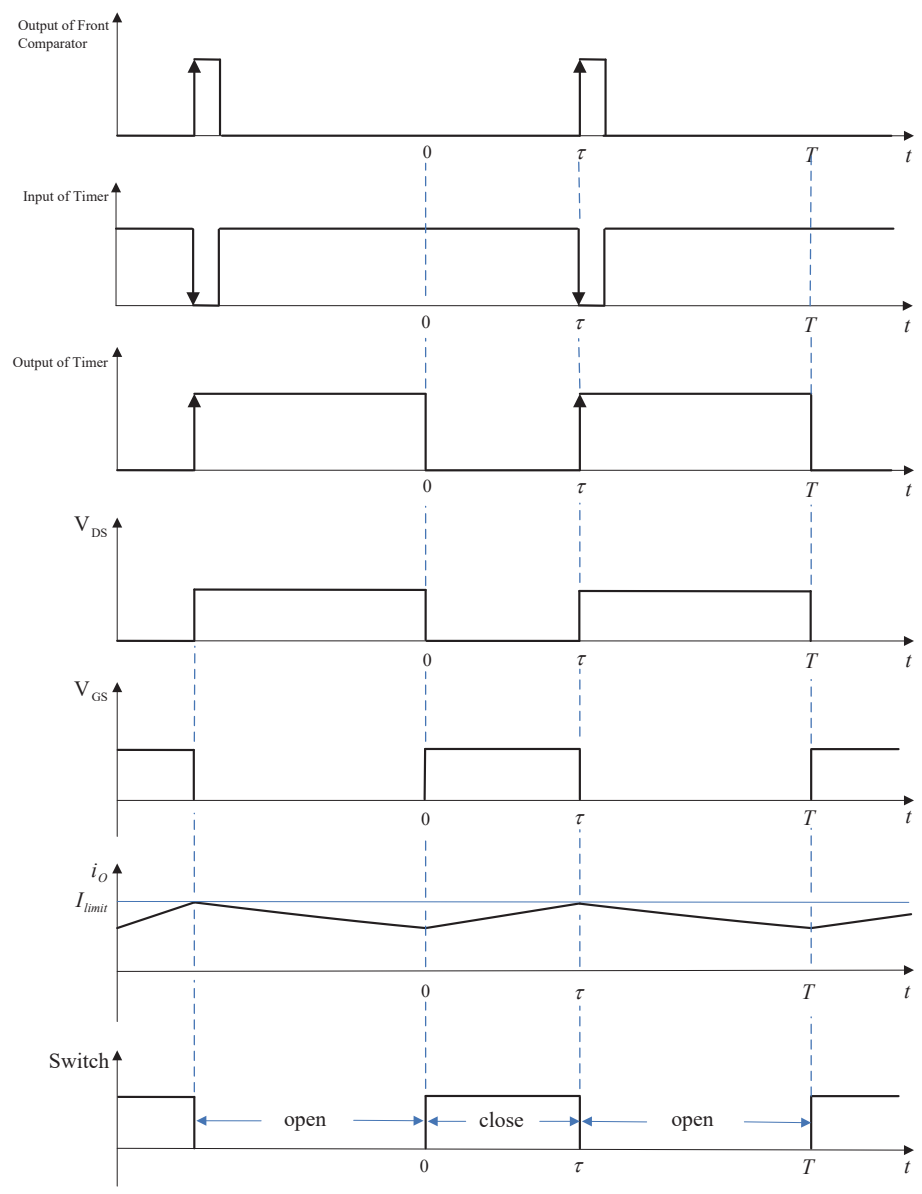

Fig. 9. Waveforms from analysis of the model. 


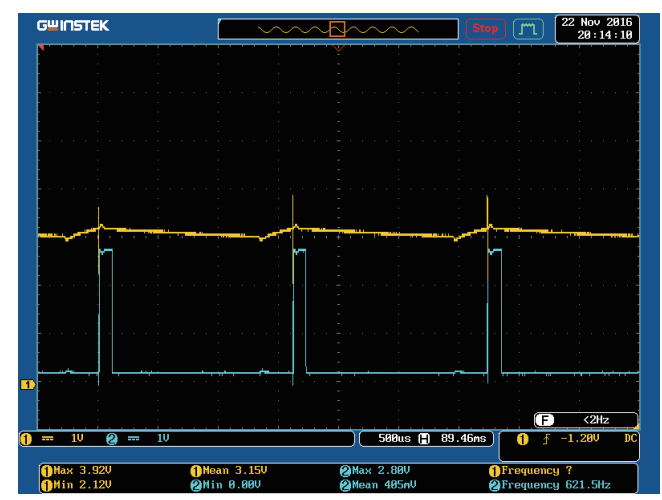

(a)

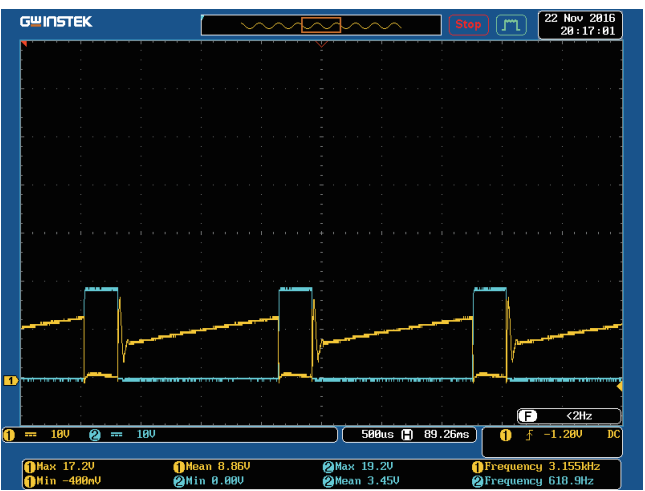

(c)

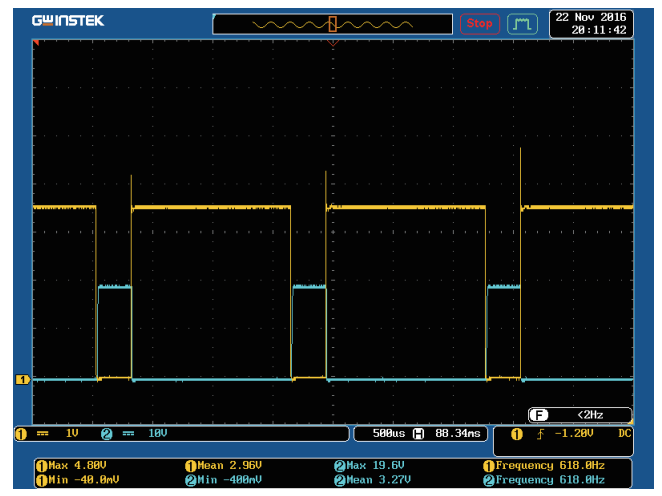

(b)

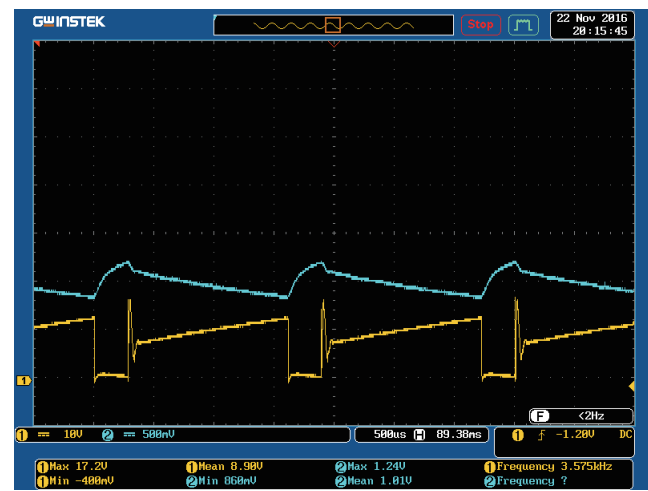

(d)

Fig. 10. (Color online) Waveforms at $I_{\text {limit }}=10 \mathrm{~A}$. (a) Output waveforms of Hall current sensor (yellow) and front comparator (blue). (b) Output waveforms of timer (yellow) and isolated circuit (blue). (c) Waveforms of $V_{D S}$ (yellow) and $V_{G S}$ (blue). (d) Waveforms of $V_{D S}$ (yellow) and $i_{O}$ (blue).

Similarly, various waveforms at $I_{\text {limit }}=20 \mathrm{~A}$ are shown in Fig. 11 . Note that $100 \mathrm{mV}$ on the scale denotes $1 \mathrm{~A}$ for $i_{O}$ as shown in Fig. 11(d).

The above results show that the performance matches the theoretical predictions. It can be concluded that

(a) The switch close time $(\approx 1.2 \mathrm{~ms})$ for $I_{\text {limit }}=20 \mathrm{~A}$ is longer than that $(\approx 0.3 \mathrm{~ms})$ for $I_{\text {limit }}=10 \mathrm{~A}$.

(b) The switch open time set by the timer remains the same $(\approx 1.2 \mathrm{~ms})$ for either $I_{\text {limit }}=20 \mathrm{~A}$ or $I_{\text {limit }}=10 \mathrm{~A}$.

(c) The ripple amplitude of output current $\left(i_{O}\right)$ for $I_{\text {limit }}=20 \mathrm{~A}$ is $0.58 \mathrm{~A}$, which is slightly higher than $0.38 \mathrm{~A}$ for $I_{\text {limit }}=10 \mathrm{~A}$.

(d) The frequency of the control signal for $I_{\text {limit }}=20 \mathrm{~A}$ is $144 \mathrm{~Hz}$, which is lower than $618 \mathrm{~Hz}$ for $I_{\text {limit }}=10 \mathrm{~A}$.

(e) The maximum $V_{D S}$ for $I_{\text {limit }}=20 \mathrm{~A}$ where the switch is open is $10.4 \mathrm{~V}$, which is lower than 17.2 $\mathrm{V}$ for $I_{\text {limit }}=10 \mathrm{~A}$.

(f) A noise signal appears during the switching transition for $I_{\text {limit }}=10 \mathrm{~A}$, which may result in slightly more power consumption in the MOSFET.

(g) An increase in the temperature of the MOSFET is not evident (below $40^{\circ}$ ) due to both driver and snubber circuits used in the model. 


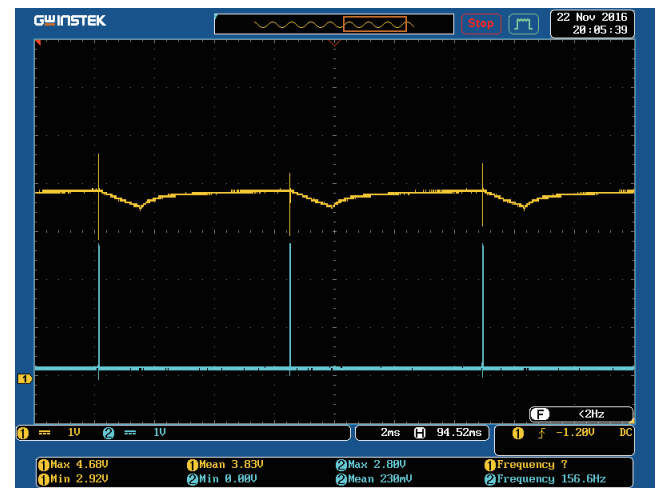

(a)

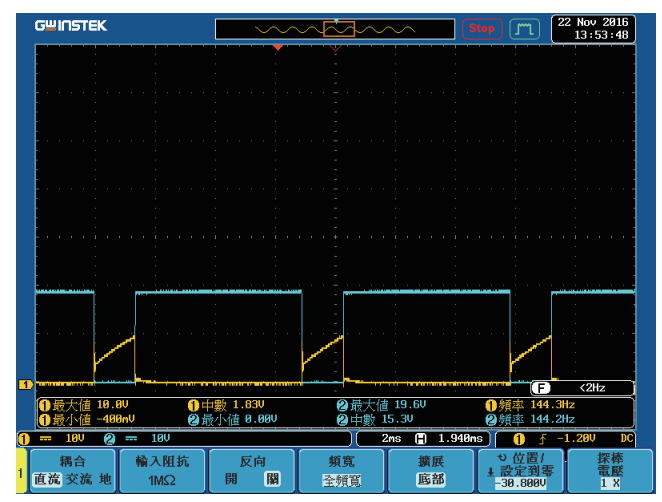

(c)

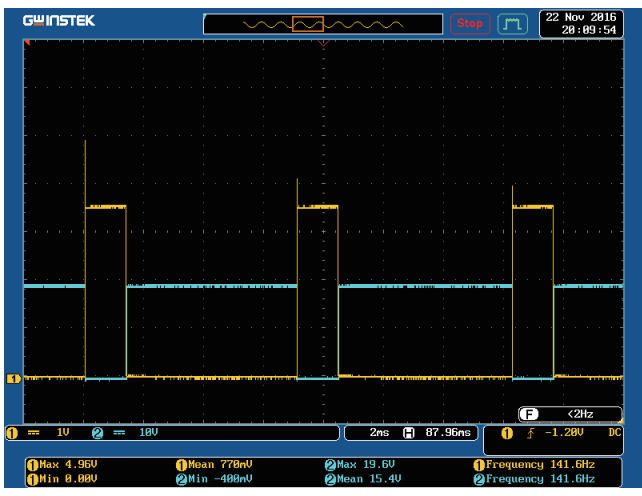

(b)

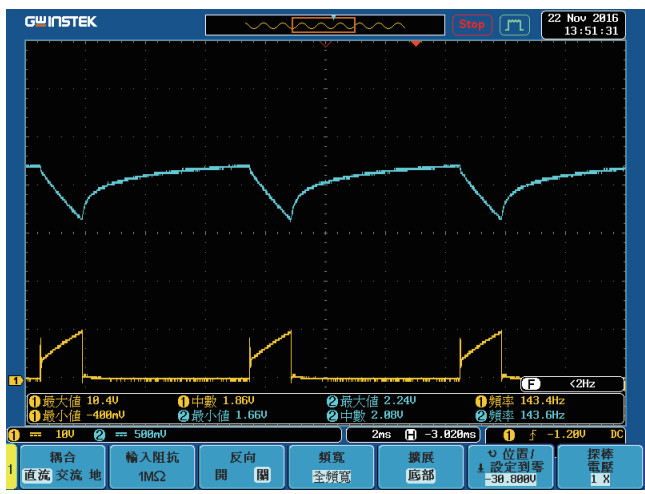

(d)

Fig. 11. (Color online) Waveforms at $I_{\text {limit }}=20 \mathrm{~A}$. (a) Output waveforms of Hall current sensor (yellow) and front comparator (blue). (b) Waveforms from outputs of timer (yellow) and isolated circuit (blue). (c) Waveforms of $V_{D S}$ (yellow) and $V_{G S}$ (blue). (d) Waveforms of $V_{D S}$ (yellow) and $i_{O}$ (blue).

\section{Conclusions}

Overload protection using a current-limiting mechanism is a crucial issue in electrical facilities. The proposed high-switching LC filtering method applying a feedback-control principle can efficiently restrict the load current in a desired range to protect from overload. The results shown in Figs. 10 and 11 revealed that the proposed model performs reasonably and effectively for current limitation for either 10 or $20 \mathrm{~A}$. The feedback control mechanism promises that the proposed model is applicable to other desired current limitations. In addition, the control signal frequency is related to the amount of limited current as well as to the delayed time set by the timer. The higher control signal frequency reduces the ripple in the output voltage/current and thus improves the frustration in the load voltage/current waveform. However, it may cause slightly higher power consumption due to increasing switch transition frequency. The driver and snubber circuit are therefore applied in this model so that it is possible to suppress the temperature increase of the MOSFET. 


\section{References}

1 P. E. Elavenil and R. Kalaivani: Lect. Notes Electr. Eng. 326 (2015) 1007.

2 M. Berger and D. Korff: Adv. Mater. Res. 1018 (2014) 357.

3 D. L. Ransom and R. Hamilton: IEEE Trans. Ind. Appl. 49 (2013) 2471.

4 A. Hazi and G. Hazi: Proc. 2014 Int. Conf. Exposition Electrical and Power Engineering (2014) p. 968.

5 P. Abirami and M. L. George: Proc. 2016 Int. Conf. Computation of Power (2016) p. 773.

6 IEEE Std 1015-2006/Cor 1-2007 (Corrigendum to IEEE Std 1015-2006), IEEE Recommended Practice for Applying Low Voltage Circuit Breakers Used in Industrial and Commercial Power Systems-Corrigendum 1 (2007) p. 1.

7 IEEE Std C37.119-2016 (Revision of IEEE Std C37.119-2005), IEEE Guide for Breaker Failure Protection of Power Circuit Breakers (2016) p. 1.

8 Y. Zhang and Y. C. Liang: Proc. 2014 IEEE Energy Conversion Congress and Exposition (IEEE 2014).

9 K. A. Corzine: IEEE Trans. Pow. Elec. 32 (2017) 1411.

10 D. Keshavarzi, T. Ghanbari, and E. Farjah: IEEE Trans. Pow. Electron. 32 (2016) 6813.

11 Z. Zhou, Z. Huang, X. Ming, B. Zhang, and Z. Li: Proc. IEEE Int. Conf. Electron Devices and Solid-State Circuits (IEEE 2009).

12 H. Peng and D. Maksimovic: Proc. 37th IEEE Power Electronics Specialists Conf. (IEEE 2006).

13 H. Choi: Proc. IEEE 32nd Annu. Conf. Industrial Electronics (IEEE 2006).

14 C. M. Bhatia, S. Malhotra, and M. K. Soni: 2010 India Int. Conf. Power Electronics (2010).

15 C. Y. Zhang, Y. Chun, and W. Yan: Appl. Mech. Mater. 543 (2014) 1219.

16 J. Y. Zhao, X. H. Ma, L. Jia, and G. X. Zhang: Aplp. Mech. Mater. 143 (2012) 8.

17 H. E. Amir and R. Iravani: IEEE Trans. Ind. Electron. 60 (2013) 5629. 